\title{
Alterações no Metabolismo da Cana-de-Açúcar em Função da APLicaÇÃo de MATURAdores ${ }^{1}$
}

\author{
Response of Sugarcane Metabolism to Ripener Application

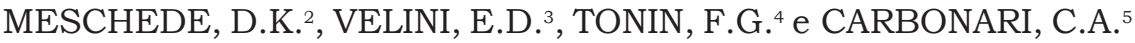

\begin{abstract}
RESUMO - O objetivo deste trabalho foi avaliar as alterações nos níveis de ácido chiquímico e ácido salicílico em plantas de cana-de-açúcar submetidas à aplicação de maturadores. Aplicou-se glyphosate nas doses de 400 e $200 \mathrm{~mL} \mathrm{ha}^{-1}$ e na dose de $150 \mathrm{~mL} \mathrm{ha}^{-1}$ em mistura com sulfumeturon-methyl a 12 e $20 \mathrm{~g} \mathrm{ha}^{-1}$ e sulfumeturon-methyl a $20 \mathrm{~g} \mathrm{ha}^{-1}$. As avaliações foram realizadas aos 15 e 30 dias após a aplicação (DAA) e aos 30, 60, 90, 120 e 150 dias após a colheita da cana-de-açúcar. Os teores de ácido chiquímico e salicílico nas plantas de canade-açúcar foram determinados por cromatografia liquida e espectrometria de massas. Os resultados mostraram que as doses de glyphosate correlacionaram-se diretamente com as concentrações de ácido chiquímico na planta, sendo superiores à da testemunha. Aos 30 DAA, houve aumento na concentração de ácido salicílico em todos os tratamentos estudados, revelando um processo de senescência da planta. Maiores doses de glyphosate promoveram aumento na concentração de ácido chiquímico e ácido salicílico antes da colheita da canade-açúcar. No período de crescimento da planta, aumentos nos teores dos ácidos chiquímico e salicílico revelaram dependência da aplicação dos produtos e também dos fatores abióticos e bióticos a que a cultura foi exposta.
\end{abstract}

Palavras-chave: ácido chiquímico, ácido salicílico, doenças, fisiologia.

\begin{abstract}
The aim of this study was to evaluate the levels of shikimic acid and salicylic acid in sugarcane plants after ripener application. Glyphosate was applied at the doses of 400 and $200 \mathrm{~mL} \mathrm{ha-1}$, with a dose of $150 \mathrm{~mL} \mathrm{ha}^{-1}$ being mixed with sulfumeturon-methylat 12 and $20 \mathrm{~g} \mathrm{ha}^{-1}$ and sulfumeturon-methyl at $20 \mathrm{~g} \mathrm{ha-1}$.Evaluations were performed at 15 and 30 days after application (DAA) and at 30, 60, 90, 120, and 150 days after sugarcane harvest. The shikimic acid and salicylic acid contents in sugarcane were determined by liquid chromatography and mass spectrometry. The results showed that the glyphosate doses were directly correlated with shikimic acid concentrations in the plants, being higher than the control. An increase in salicylic acid concentration was observed at 30 DAA for all treatments, revealing a process of plant senescence. Higher glyphosate doses led to increased concentrations of shikimic acid and salicylic acid before sugarcane harvest. During plant growth, increases in shikimic acid and salicylic acid levels showed dependence on application of products and on the biotic and abiotic factors to which the culture had been exposed.
\end{abstract}

Keywords: shikimic acid;salicylic acid,diseases, physiology.

\section{INTRODUÇÃO}

O efeito dos herbicidas sobre as plantas cultivadas é um importante aspecto muitas vezes negligenciado, uma vez que pode influenciar vários processos fisiológicos, inclusive a sua suscetibilidade a doenças (Duke et al., 2006). É fato que o uso inadequado de herbicidas e fitorreguladores pode originar ou incrementar as severidades fitopatológicas (Griffits, 1981).

1 Recebido para publicação em 22.2.2011 e aprovado em 12.8.2011.

2 Pesquisadora, D.Sc., Dep. de Produção Vegetal, FCA/UNESP, <meschede@fca.unesp.br>; 3 Professor Adjunto, Dep. de Produção Vegetal, FCA/UNESP, <velini@fca.unesp.br>; ${ }^{4}$ Professor, D.Sc., Faculdade de Zootecnia e Engenharia de Alimentos Pirassununga, FZEA/USP; ${ }^{5}$ Engo-Agrọ., D.Sc., Dep. de Produção Vegetal, FCA/UNESP, <carbonari@fca.unesp.br>. 
Em torno de $20 \%$ de todo o carbono fixado pelas plantas passa pela rota do ácido chiquímico. Um dos aspectos importantes dessa rota é a inibição, pelo herbicida glyphosate, da enzima 5-enol-piruvil-shikimato-3fosfato sintetase (EPSPs), responsável por uma das etapas da sintese de aminoácidos aromáticos. O bloqueio da rota do chiquimato leva ao acúmulo de altos níveis de ácido chiquímico e, consequentemente, a uma redução nos níveis desses aminoácidos, a partir dos quais são formados metabólitos secundários, como as fitoalexinas, envolvidos na resposta das plantas aos fitopatógenos, aumentando a suscetibilidade às doenças (Duke et al., 2005).

De acordo com Anderson et al. (2001), um bioindicador ideal para plantas expostas ao glyphosate deve ser específico para esse herbicida, desenvolver-se rapidamente no interior da célula, aí permanecendo durante algum tempo, e ser relativamente fácil de extrair e analisar a baixo custo. Nesse contexto, o ácido chiquímico tem demonstrado ser um marcador seletivo para plantas expostas a subdoses de glyphosate (Harring et al., 1998; Singh \& Shaner, 1998; Wang, 2001; Mueller et al., 2003).

O ácido salicílico é o principal composto sinalizador para o desenvolvimento da resistência de plantas a patógenos e também a estresses abióticos e algumas pragas. Esse ácido é produzido a partir da fenilalanina, um dos três aminoácidos aromáticos cuja síntese é bloqueada pelo glyphosate.

A análise das informações disponiveis indica que, para que uma planta seja resistente a patógenos biotróficos (que não promovem a morte das células parasitadas, como as viroses, ferrugens, carvões e outros), é necessário que ela produza e acumule o ácido salicílico, além de apresentar os genes corretos de resistência. A falha na produção desse ácido leva à suscetibilidade, que pode, por sua vez, ser revertida pela aplicação exógena do composto, demonstrando a participação inequivoca do ácido salicílico como indutor da resistência. Baixas doses de glyphosate podem inibir a síntese de ácido salicílico e aumentar a suscetibilidade de plantas a doenças.

Diante da possibilidade de o uso de herbicidas em doses reduzidas interferir na sintese dos ácidos chiquímico e salicílico e, consequentemente, alterar o metabolismo de defesa da planta, objetivou-se neste trabalho verificar os acúmulos de ácido chiquímico e salicílico em plantas de cana-de-açúcar submetidas à aplicação de glyphosate e sulfumeturonmethyl como maturadores.

\section{MATERIAL E MÉTODOS}

O experimento foi conduzido em cana-soca de segundo corte, variedade SP 803280, na Fazenda Jurema, no município de Igaraçu do Tietê-SP (latitude de $22^{\circ} 38^{\prime} 45^{\prime \prime}$, longitude de $48^{\circ} 36^{\prime} 29^{\prime \prime} \mathrm{W}$ e altitude de $620 \mathrm{~m}$ ).

Cada parcela foi constituída de $160 \mathrm{~m}^{2}$ (1,6 m entre plantas, em 10 linhas, e $10 \mathrm{~m}$ de comprimento), totalizando uma área de $960 \mathrm{~m}^{2}$. Como área útil foram consideradas as cinco linhas centrais. Os tratamentos constituíram-se da aplicação dos herbicidas sulfumeturon-methyl (750 g de i.a. kg-1) e glyphosate (360 e.a. $\left.\mathrm{kg}^{-1}\right)$. As doses utilizadas foram: glyphosate a $72 \mathrm{~g} \mathrm{ha}^{-1}(200 \mathrm{~mL}$ p.c. ha-1 $)$; glyphosate a $144 \mathrm{~g} \mathrm{ha}^{-1}(400 \mathrm{~mL}$ p.c. ha-1); glyphosate a $72 \mathrm{~g} \mathrm{ha}^{-1}\left(200 \mathrm{~mL}\right.$ p.c. ha-1 ${ }^{-1}$ sulfumeturon-methyl a 10 g p.c ha $^{-1}$ ); glyphosate a $54 \mathrm{~g} \mathrm{ha}^{-1}\left(150 \mathrm{~mL}\right.$ p.c. ha $\mathrm{h}^{-1}+$ sulfumeturon-methyl a 12 g p.c. ha-1); sulfumeturon-methyl a 20 g p.c. ha ${ }^{-1}$; e a testemunha sem aplicação de maturadores.

A aplicação dos produtos foi feita em 11 de outubro de 2006, utilizando equipamento costal pressurizado $\left(\mathrm{CO}_{2}\right)$ com barra contendo seis pontas de pulverização AXI 11002, sendo a pressão de trabalho de 50 psi e o volume de calda de $100 \mathrm{~L} \mathrm{ha}^{-1}$. A umidade relativa do ar no momento da aplicação foi de $80 \%$, com velocidade do vento de $6 \mathrm{~ms}^{-1}$ e temperatura média de $25^{\circ} \mathrm{C}$.

As avaliações na área experimental foram realizadas aos 15 e 30 dias após aplicação dos herbicidas (DAA), antes da colheita da cana-deaçúcar e após a colheita; a soqueira da canade-açúcar foi avaliada aos 30, 60, 90, 120, 150 e 180 dias após colheita (DAC).

Nas datas de avaliação, foram amostradas aleatoriamente 15 plantas por parcela, sendo coletadas as folhas do ponteiro. As folhas foram secas em estufa de circulação forçada a $60^{\circ} \mathrm{C}$ por 72 horas e, em seguida, trituradas em moinho do tipo Willey. 
Para análise dos ácidos chiquímico e salicílico, foi realizada a pesagem de $400 \mathrm{mg}$ de cada uma das amostras, que foram adicionadas a $10 \mathrm{~mL}$ de água a $\mathrm{pH} 7,0$ em béquer de vidro de $50 \mathrm{~mL}$ de capacidade, sendo colocados individualmente no centro do disco de um forno micro-ondas (Panasonic Model NN-S62 B) durante 20 segundos na potência de $100 \mathrm{~W}$ a uma temperatura média de $49.8^{\circ} \mathrm{C}\left( \pm 2.8^{\circ} \mathrm{C}\right)$, conforme Matallo et al. (2009). Após o esfriamento, a amostra foi filtrada em filtro de papel Whatmann no 1 e filtro de membrana Millex GV (Millipore).

As análises foram realizadas em cromatógrafo líquido e espectrômetro de massas (LCMS), da marca Shimadzu, cujas características foram: bomba LC-20AD; injetor SIL-10AF; forno CTO-10AS vp; controladora CBM-20 A; degaseificador DGU-20A5; e espectrômetro de massa LCMS- 2010 EV. O método analítico empregou coluna Gemini (Phenomenex) C18, tamanho de partícula de $5 \mathrm{~nm}$, dimensões 150 x 4,6 mm; fase móvel A: água com 0,5\% de ácido acético; fase móvel B: metanol e 0,5\% de ácido acético; vazão de $0,4 \mathrm{~L} \mathrm{~min}^{-1}$; temperatura do forno de $30{ }^{\circ} \mathrm{C}$; tipo de ionização em modo negativo; $\mathrm{m} / \mathrm{z}$ ácido chiquímico: 173 ; $\mathrm{m} / \mathrm{z}$ ácido salicílico: 137; condição do tunning do equipamento efetuado por rotina própria, utilizando-se polietilenoglicol como padrão. Após vários testes, foi determinado o tempo total de corrida dos ácidos, que foi de 20 minutos; o tempo de retenção do ácido chiquímico foi de 5 minutos $( \pm 0,1)$, e o do ácido salicílico, de 19 minutos $( \pm 0,1)$.

Os resultados foram submetidos à análise de variância pelo teste $\mathrm{F}(5 \%$ de probabilidade) e utilizou-se o teste T ( $5 \%$ de probabilidade) para a comparação entre as médias. A probabilidade para comparação entre os tratamentos e a testemunha foi calculada: $1 /\left(100 * 2^{\mathrm{n}-2 \mathrm{xmenor}}\right)$, em que $\mathrm{x}=$ valores acima da linha de tendência e $\mathrm{y}=$ valores abaixo da linha de tendência.

\section{RESULTADOS E DISCUSSÃO}

As plantas expostas às diferentes doses de glyphosate apresentaram sempre as maiores concentrações de ácido chiquímico tanto nas avaliações aos 15 DAA como aos 30 DAA. Quanto maior a dose de glyphosate, maior a concentração acumulada de ácido chiquímico, e essa diferença chegou até a 20\% (Tabela 1). Matallo et al. (2009), trabalhando com glyphosate e concentração de ácido chiquímico em citros, observaram que as plantas que receberam aplicação de glyphosate mostraram sempre maiores concentrações de ácido chiquímico que as plantas testemunhas. Vários pesquisadores (Singh \& Shaner, 1998; Wang, 2001; Mueller et al., 2003) têm demonstrado que o ácido chiquímico é um marcador seletivo para plantas expostas a subdoses

Tabela 1 - Concentração de ácido chiquímico e ácido salicílico em cana-de-açúcar, variedade SP 803280, 15 e 30 DAA dos herbicidas - Igaraçu do Tietê-SP, 2006

\begin{tabular}{|c|c|c|c|c|}
\hline \multirow{3}{*}{ Tratamento } & \multicolumn{4}{|c|}{ Concentração $\left(\mathrm{mg} \mathrm{kg}^{-1}\right)$} \\
\hline & \multicolumn{2}{|c|}{ ácido chiquímico } & \multicolumn{2}{|c|}{ ácido salicílico } \\
\hline & $15 \mathrm{DAA}$ & $30 \mathrm{DAA}$ & $15 \mathrm{DAA}$ & 30 DAA \\
\hline 1. glyphosate $200 \mathrm{~mL} \mathrm{ha}^{-1}$ & $65,56 \mathrm{a}$ & $59,28 \mathrm{~b}$ & $0,33 \mathrm{~b}$ & $0,59 \mathrm{~b}$ \\
\hline 2. glyphosate $400 \mathrm{~mL} \mathrm{ha}^{-1}$ & $70,97 \mathrm{a}$ & $68,98 \mathrm{a}$ & $0,55 \mathrm{a}$ & $1,45 \mathrm{a}$ \\
\hline 3. glyph $^{1 /} 200 \mathrm{~mL} \mathrm{ha}^{-1}+$ sulf-methyl ${ }^{2 /} 10 \mathrm{~g} \mathrm{ha}^{-1}$ & $57,40 \mathrm{~b}$ & $56,24 \mathrm{~b}$ & $0,45 \mathrm{~b}$ & $0,65 \mathrm{~b}$ \\
\hline 4. glyph. $150 \mathrm{~mL} \mathrm{ha}^{-1}+$ sulf-methyl $12 \mathrm{~g} \mathrm{ha}^{-1}$ & $55,86 \mathrm{~b}$ & $62,48 \mathrm{~b}$ & $0,39 \mathrm{~b}$ & $0,46 \mathrm{~b}$ \\
\hline 5. sulfumeturon-methyl $20 \mathrm{~g} \mathrm{ha}^{-1}$ & $56,22 \mathrm{~b}$ & $49,18 \mathrm{~b}$ & $0,36 \mathrm{~b}$ & $0,66 \mathrm{~b}$ \\
\hline 6. Testemunha & $57,47 \mathrm{~b}$ & $49,30 \mathrm{~b}$ & $0,30 \mathrm{c}$ & $0,49 \mathrm{~b}$ \\
\hline $\mathrm{F}$ tratamento & 0,0275 & 0,035 & 0,016 & 0,027 \\
\hline F bloco & 1,45 & 1,23 & 1,94 & 1,194 \\
\hline $\mathrm{CV}(\%)$ & 18,90 & 15,90 & 35,93 & 24,35 \\
\hline DMS & 9,85 & 6,03 & 0,15 & 0,42 \\
\hline
\end{tabular}

Médias seguidas de mesma letra, na coluna, não diferem estatisticamente pelo teste de t a $5 \%$ de probabilidade. ${ }^{1 /}$ Glyp. = glyphosate, $\stackrel{2 /}{=}$ sulfmethyl $=$ sulfumeturon-methyl. 
de glyphosate. Niveis elevados de ácido chiquímico, detectados a partir de aplicações de glyphosate, foram observados em Conyza canadensis (Mueller et al., 2003; Koger et al., 2005), algodão (Pline et al., 2002), girassol, trigo e milheto (Henry et al., 2007), soja (Singh \& Shaner 1998) e trigo (Bresnahan et al., 2003).

Com o transcorrer do tempo, o teor de ácido chiquímico apresentou tendência de queda para todas as doses e misturas; o decréscimo variou de 5 a $15 \%$ em relação à concentração observada na primeira avaliação (15 DAA), exceto para o tratamento com a mistura de glyphosate e sulfumeturon-methyl na menor dose. Bresnahan et al. (2003), verificando a concentração de ácido chiquímico com aplicação de glyphosate na cultura do trigo, observaram que o pico de concentração foi entre 7 e 10 dias após a aplicação e que os teores foram diminuindo até a colheita. Corroborando essa informação, Koger et al. (2005) observaram que os picos de acumulação de ácido chiquímico ocorrem até 14 dias após o tratamento e que altos niveis foram detectados até 28 dias depois da aplicação do glyphosate.

Ainda na Tabela 1, observa-se que, quanto maior a concentração de ácido chiquímico, maior a concentração de ácido salicílico na cana. A concentração de ácido salicílico em plantas que receberam a maior dose de glyphosate foi $40 \%$ maior do que nas plantas testemunhas e, em média, 20\% maior com relação aos demais tratamentos. Esse resultado é o contrário do que se esperava, isto é, acreditava-se que a inibição da EPSPs, pela aplicação do glyphosate, promoveria um desvio da rota do ácido chiquímico, impedindo ou diminuindo a sua biossintese, já que a principal enzima da via do ácido chiquímico é a fenilalanina amônio liase (PAL).

Para Sticher et al. (1997), um fato ainda controverso é se o ácido salicílico é um sinal para a síntese de si mesmo (ácido salicílico endógeno por sintese em redundância) ou se um sinal secundário existe e se transloca para levar a mensagem de síntese de ácido salicílico endógeno a locais mais distantes.

Assim, mesmo que ocorra redução na biossintese de salicílico pela inibição da rota do ácido chiquímico, a planta tem um caminho alternativo ou secundário para a síntese deste, isto é, a produção do salicílico depende do metabolismo da planta e dos fatores estressantes a que ela é submetida. Como exemplo, Pseudomonas putida possui genes que codificam para sintese da enzima salicilatohidroxilase. Essa enzima está envolvida com o metabolismo de naftaleno e também com a conversão de ácido salicílico; portanto, plantas infectadas com $P$. putida tiveram seus teores de ácido salicílico aumentados (Romeiro, 2009).

Aos 30 dias após a aplicação dos tratamentos, a maior concentração de ácido salicílico foi obtida com aplicação de glyphosate; o aumento foi três vezes maior que o observado na primeira época de avaliação (15 DAA). Em todos os tratamentos houve aumento em média de 40\% na concentração de ácido salicílico na planta, em relação à primeira época de avaliação. Esse resultado pode estar relacionado ao processo de estresse da planta devido ao aumento da morte celular provocada pela aplicação do glyphosate e sulfumeturon-methyl e/ ou pela própria maturação natural da cultura.

Durante a avaliação de crescimento da cana-soca, observa-se diferença significativa somente para o tratamento que recebeu aplicação de glyphosate na maior dose, porém com valores muito inferiores ao observado na précolheita (Tabela 2).

Assim como o ácido chiquímico, as concentrações de ácido salicílico só apresentaram diferenças significativas entre os tratamentos no início das avaliações, embora os tratamentos com glyphosate e sulfumeturon-methyl sempre tenham apresentado valores superiores ao da testemunha (Tabela 3). Radicais livres são formados sob condições de estresse oxidativo pela aplicação de herbicidas, mas isso é altamente regulado (Chaoui et al., 1997; Mazhoudi et al., 1997; Greggains et al., 2000); todavia, essa regulação pode ser perdida, principalmente em função da dose, se o estresse for mais severo, aumentando consideravelmente a produção de radicais livres, que podem levar a uma cascata de eventos e alterações metabólicas.

Reações metabólicas da planta e a produção de ácido salicílico podem ser evidenciadas na avaliação realizada aos 60 dias após 
Tabela 2 - Concentração de ácidos chiquímico e salicílico durante o crescimento da cana-soca, variedade SP 803280. Igaraçu do Tietê-SP, 2007

\begin{tabular}{|c|c|c|c|c|c|}
\hline \multirow{2}{*}{ Tratamento } & \multicolumn{5}{|c|}{ Ácido chiquímico $\left(\mathrm{mg} \mathrm{kg}^{-1}\right)$} \\
\hline & $30 \mathrm{DAC}$ & $60 \mathrm{DAC}$ & $90 \mathrm{DAC}$ & $120 \mathrm{DAC}$ & $150 \mathrm{DAC}$ \\
\hline 1. glyphosate $200 \mathrm{~mL} \mathrm{ha}^{-1}$ & $17,3 \mathrm{a}$ & 25,7 & 12,0 & 7,3 & 14,0 \\
\hline 2. glyphosate $400 \mathrm{~mL} \mathrm{ha}^{-1}$ & $23,0 \mathrm{a}$ & 32,0 & 13,3 & 7,3 & 17,7 \\
\hline 3. glyph $^{1 /} 200 \mathrm{~mL} \mathrm{ha}^{-1}+$ sulf-methyl $\mathrm{l}^{2 /} 10 \mathrm{~g} \mathrm{ha}^{-1}$ & $16,1 \mathrm{~b}$ & 25,0 & 13,3 & 7,0 & 14,7 \\
\hline 4. glyp $150 \mathrm{~mL} \mathrm{ha}^{-1}+$ sulf-methyl $12 \mathrm{~g} \mathrm{ha}^{-1}$ & $18,0 \mathrm{~b}$ & 30,0 & 13,0 & 7,3 & 13,0 \\
\hline 5. sulfumeturon-methyl $20 \mathrm{~g} \mathrm{ha}^{-1}$ & $16,0 \mathrm{~b}$ & 24,0 & 12,7 & 7,3 & 11,7 \\
\hline 6. Testemunha & $13,3 \mathrm{~b}$ & 20,0 & 11,7 & 7,3 & 13,3 \\
\hline F tratamento & $0,006^{*}$ & $0,722^{\mathrm{ns}}$ & $0,957^{\mathrm{ns}}$ & $0,984^{\mathrm{ns}}$ & $0,397^{\mathrm{ns}}$ \\
\hline F bloco & 1,33 & 5,72 & 1,57 & 0,38 & 1,91 \\
\hline CV $(\%)$ & 13,20 & 37,70 & 21,46 & 9,16 & 23,66 \\
\hline DMS & 4,10 & 17,62 & 4,83 & 1,18 & 5,92 \\
\hline
\end{tabular}

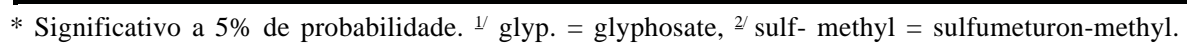

Tabela 3 - Concentração de ácido salicílico durante o crescimento da cana-soca, variedade SP 803280. Igaraçu do Tietê-SP, 2007

\begin{tabular}{|c|c|c|c|c|c|}
\hline \multirow{2}{*}{ Tratamento } & \multicolumn{5}{|c|}{ Ácido salicílico $\left(\mathrm{mg} \mathrm{kg}^{-1}\right)$} \\
\hline & $30 \mathrm{DAC}$ & $60 \mathrm{DAC}$ & $90 \mathrm{DAC}$ & $120 \mathrm{DAC}$ & $150 \mathrm{DAC}$ \\
\hline 1. glyphosate $200 \mathrm{~mL} \mathrm{ha}^{-1}$ & $4,7 \mathrm{~b}$ & $49,3 \mathrm{a}$ & 5,7 & 9,7 & 9,7 \\
\hline 2. glyphosate $400 \mathrm{~mL} \mathrm{ha}^{-1}$ & $5,0 \mathrm{a}$ & $37,7 \mathrm{~b}$ & 3,0 & 15,3 & 11,3 \\
\hline 3. glyph $^{1 /} 200 \mathrm{~mL} \mathrm{ha}^{-1}+$ sulf-methyl $^{2 /} 10 \mathrm{~g} \mathrm{ha}^{-1}$ & $3,7 \mathrm{~b}$ & $37,0 \mathrm{~b}$ & 2,0 & 6,7 & 8,0 \\
\hline 4. glyp $150 \mathrm{~mL} \mathrm{ha}^{-1}+$ sulf-methyl $12 \mathrm{~g} \mathrm{ha}^{-1}$ & $4,3 \mathrm{~b}$ & $44,7 \mathrm{~b}$ & 2,0 & 9,7 & 10,7 \\
\hline 5. sulfumeturon-methyl $20 \mathrm{~g} \mathrm{ha}^{-1}$ & $4,3 \mathrm{~b}$ & $40,7 \mathrm{~b}$ & 5,3 & 14,0 & 10,0 \\
\hline 6. Testemunha & $3,3 \mathrm{~b}$ & $36,7 \mathrm{~b}$ & 2,7 & 6,0 & 7,7 \\
\hline F tratamento & $0,068^{*}$ & $0,029^{*}$ & $0,531^{\mathrm{ns}}$ & $0,473^{\mathrm{ns}}$ & $0,486^{\text {ns }}$ \\
\hline F bloco & 0,56 & 4,27 & 1,76 & 3,83 & 1,49 \\
\hline $\mathrm{CV}(\%)$ & 22,14 & 18,08 & 38,7 & 35,07 & 27,13 \\
\hline DMS & 1,72 & 13,18 & 5,43 & 11,83 & 4,61 \\
\hline
\end{tabular}

* Significativo a $5 \%$ de probabilidade. ${ }^{1 /}$ glyp. = glyphosate, $\stackrel{2}{2}$ sulf- methyl = sulfumeturon-methyl.

colheita, em que se observa aumento generalizado de 10 vezes na concentração desse ácido na planta. Esse aumento pode estar relacionado à resposta da cana-de-açúcar a um agente estressante (provavelmente a falta de chuva).

Comparando a aplicação de glyphosate e sulfumeturon-methyl em relação à testemunha, observou-se que a aplicação desses produtos aumentou as concentrações de ácidos chiquímico e salicílico na planta (Figuras 1 e 2). Mais do que a possibilidade da absorção de glyphosate pela planta, seja por deriva ou por transferência via rizosfera (Neumann et al., 2006), a diferença observada nos teores de ácidos chiquímico e salicílico pode ser atribuída principalmente a fatores bióticos e abióticos.
A interação entre a concentração de ácido salicílico e a de chiquímico é apresentada na Figura 3. Aumentos nos niveis de ácido chiquímico promovem aumentos nos niveis do ácido salicílico, porém essa relação não pode ser explicada somente pela aplicação dos herbicidas: a resposta está relacionada provavelmente ao metabolismo da planta, em resposta a estresse abiótico e biótico, como já discutido anteriormente.

Assim, a defesa da planta pode ser alterada pela aplicação dos herbicidas estudados, dependendo principalmente da dose e dos fatores bióticos e abióticos a que a cultura está submetida. As concentrações de ácido chiquímico e ácido salicílico são alteradas pela 

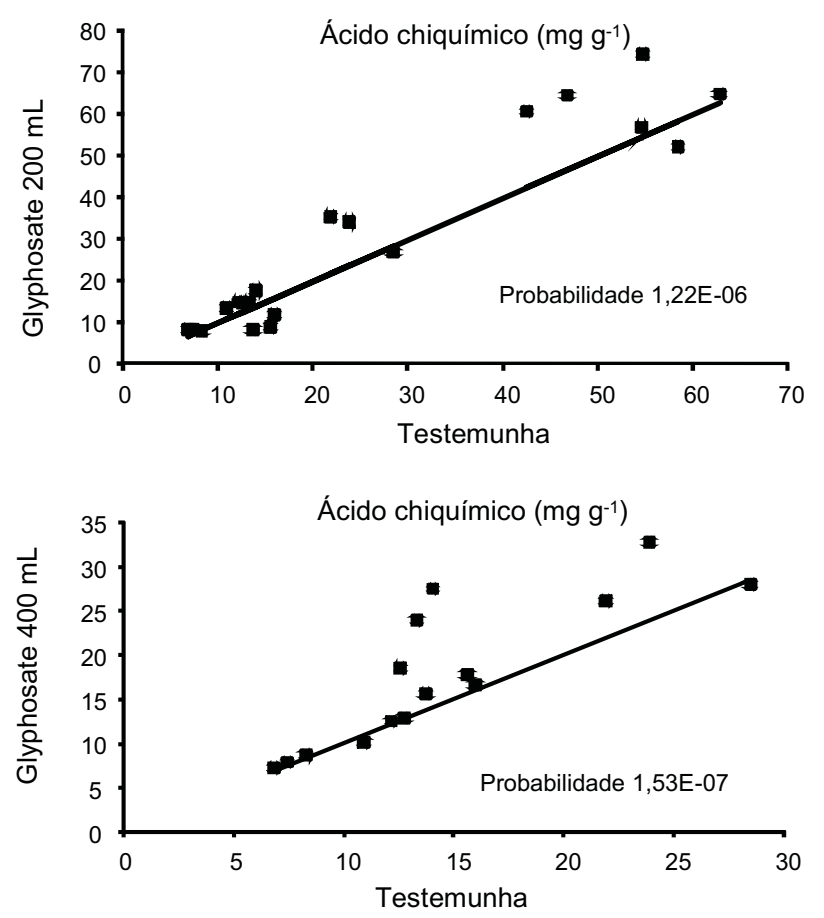

Figura 1 - Comparação entre as concentrações de ácido chiquímico observadas em cana-de-açúcar para a aplicação de glyphosate nas doses de 400 e $200 \mathrm{~mL}$ do p.c. ha-1 e a testemunha. Igaraçu do Tietê-SP, 2007.
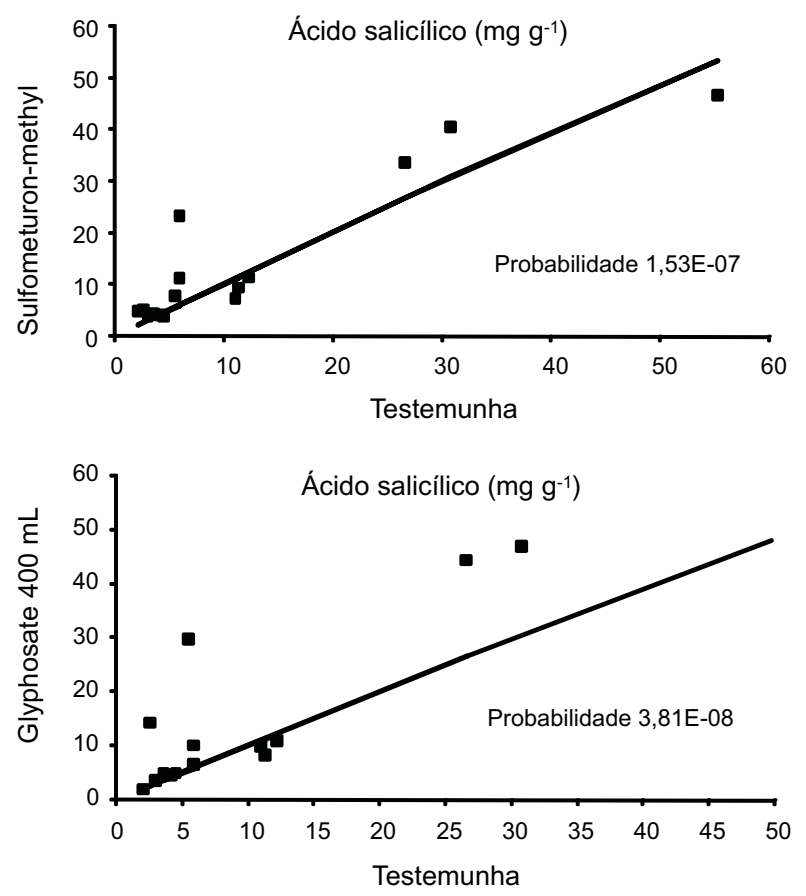

Figura 2 - Concentrações de ácido salicílico observadas na canade-açúcar para a aplicação de glyphosate e sulfumeturonmethyl, em relação à testemunha. Igaraçu do Tietê-SP, 2007.

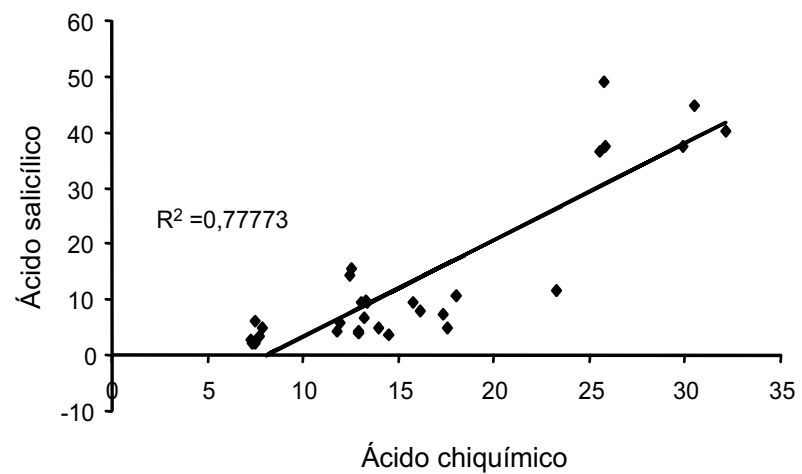

Figura 3 - Interação entre ácido chiquímico e ácido salicílico $\left(\mathrm{mg} \mathrm{g}^{-1}\right)$, influenciada pelas aplicações de glyphosate e sulfumeturon-methyl, em diferentes doses e misturas. Igaraçu do Tietê-SP, 2007.

aplicação do glyphosate e sulfumeturonmethyl, com aumentos significativos após a aplicação destes. As concentrações de ácidos salicílico e chiquímico na planta são aumentadas não só pela aplicação de herbicidas, mas também em decorrência de alterações metabólicas e condições edafoclimáticas.

\section{LITERATURA CITADA}

ANDERSON, K. A.; COBB, W. T.; LOPER, B. R. Analytical method for determination of shikimic acid: shikimic acid proportional to glyphosate application rates. Comm. Soil Sci. Plant Anal., v. 32, n. 17/18, p. 2831-2840, 2001.

BRESNAHAN, G. A. et al. Glyphosate applied preharvest induces shikimic acid accumulation in hard red spring wheat (Triticuma estivum). J. Agric. Food Chem., v. 51, n. 14, p. 4004-4007, 2003.

CHAOUI, A. et al. Cadmium and zinc induction of lipid peroxidation and effects on antioxidant enzymes activities in bean (Phaseolus vulgaris L.). Plant Sci., v. 127, n. 2, p. 139-147, 1997.

DUKE, S. O. et al. Herbicide effects on plant disease. Outlooks Pest Manag., v. 18, n. 4, p. 36-40, 2005.

DUKE, S. O. et al. Interactions of synthetic herbicides with plant disease and microbial herbicides. In: GRESSEL M. V. J. (Eds.). Novel biotechnologies for biocontrol agent enhancement and management. Boca Raton: 2006. p. 277-296.

GREGGAINS, V. et al. Metabolism-induced free radical activity does not contribute significantly to loss of viability in moist-stored recalcitrant seeds of contrasting species. New Phytol., v. 148, n. 4, p. 267-276, 2000. 
GRIFFITS, E. Iatrogenic plant diseases. Ann. Rev.

Phytopatol., v. 19, n. 1, p. 69-82, 1981.

HARRING, T.; STEIBEIG, J. C.; HUSTED, S. Accumulation of shikimic acid: A technique for screening glyphosate efficacy. J. Agric. Food Chem., v. 46, n. 2, p. 4406-4412, 1998.

HENRY, B. W.; SHANER, D. L.; WEST, M. S. Shikimate accumulation in sunflower, wheat and proso millet after glyphosate application.Weed Sci., v. 55, n. 4, p. 1-5, 2007.

KOGER, C. H. et al. Rice (Oryza sativa) response to drift rates of glyphosate. Pest.Sci., v. 61, n. 12, p. 1161-1167, 2005.

MATALLO, M. B. et al. Microwave-assisted solvent extraction and analysis of shikimic acid from plant tissues.

Planta Daninha, v. 27, p. 987-994, 2009. (Numero Especial)

MAZHOUDI, S. et al. Response of antioxidant enzymes excess copper in tomato (Lycopersicon esculentum Mill). Plant Sci., v. 127, n. 11, p. 129-137, 1997.

MUELLER, T. C. et al. Shikimate accumulates in both glyphosate-sensitive and glyphosate-resistant horseweed (Conyza canadensis L. Cronq.). J. Agric. Food Chem., v. 51, n. 3, p. 680-84, 2003.
NEUMANN, G. et al. Relevance of glyphosate transfer to non-target plants via the rhizosphere. J. Plant Dis. Protec. v. 20, p. 963-969, 2006. (Special Issue)

PLINE, W. A. et al. Tolerance and accumulation of shikimic acid in response to glyphosate applications in glyphosateresistant and nonglyphosate-resistant cotton (Gossypium hirsutum L.) J. Agric. Food Chem., v. 50, n. 3, p. 506-512, 2002.

ROMEIRO, R. S. Indução de resistência em plantas a patógenos pela microbiolização de sementes com PGPR. Disponível em: <http://www.ufv.br/dfp/bac/pelotas.html>. Acesso em: 17 jan. 2009.

SINGH, B. K.; SHANER, D. L. Rapid determination of glyphosate injury to plants and identification of glyphosateresistant plants.Weed Technol., v. 12, n. 3, p. 527-530, 1998.

STICHER, L.; MAUCH MANI, B.; METRAUX, J. P. Systemic acquired resistance. Ann. Rev. Phytopathol., v. 35, n. 3, p. 235-270, 1997.

WANG, C. Effect of glyphosate on aromatic acid metabolism in purple nutsedge (Cyperusrotundus). Weed Technol., v. 15, n. 4, p. 628-635, 2001. 